\title{
Features of the contemporary stage of the use of multimedia and information and communication technologies in teaching the mother tongue
}

\author{
Olga M. Aleksandrova ${ }^{1, *}$, and Yulia N. Gosteva ${ }^{1}$ \\ ${ }^{1}$ ISED RAE, Center of Philological Education, 105062, Moscow, Russia
}

\begin{abstract}
The article emphasizes the relevance of the use of modern means of multimedia in teaching the Russian language in the changing social and cultural milieu. Multilevel social inquiry and practice of modern education necessitated comprehensive study and the special project of the educational process of learning the Russian language with the use of multimedia and communication technologies. The analysis of monographic and methodological literature and dissertation research results have revealed some features of the present stage of the use of multimedia and information and communication technologies in Russian language teaching.
\end{abstract}

Scientists - linguodidacticians realized the need for new approaches in teaching the Russian language. The idea of introduction in the process of learning competenceoriented approach reflects the need to improve the efficiency of the learning process, the quality of education through the use of the learning process of modern methods and forms of education, enhancing activity component and taking into account the peculiarities of personality development. One of such approaches is the use of multimedia and information and communication technologies. The meaning of the term "technology" is still being specified, the term is used in quite a broad context. In practice, there are also such terms as pedagogical technology, technology of education, new pedagogical, innovative training technologies.

In modern didactics, the term "pedagogical technology" is more common in many methodological works. The stages of development of the concept of "pedagogical technology" can be outlined: the use of audiovisual aids in the learning process (40's - mid 50 's), programmed instruction (mid 50's - 60's ) to the pre-designed educational processes ensuring the achievement of clearly defined objectives (to 70's ), to the creation of computer and information technology training (from the beginning of the 80's).

Really, "new pedagogical technologies come in the practice of education" [6]. The need for this is due to a change in the society demands and the internal needs of the education system [4]. Today, students usually have experience with a variety of multimedia processing tools, transmission, storage and submission of information in everyday life and experience a great interest in their use as a means for recreation. However, the action-packed computer games frequently are the subject of interest, to a lesser degree of interest are education programs [5]. It is obvious that there must be such a model of the educational process that would ensure not only the formation of the efficient use of computer skills during the preparation and processing of the necessary educational and valuable information, but also the development of personal qualities, values of the citizen of the information society.

The study of practical experience has shown that the use of information technologies in teaching the Russian language is not a mass phenomenon. Among the reasons there are not only unresolved organizational and pedagogical issues, but also the lack of readiness of the teacher to the solution of the tasks related to the computerization of the educational process. The reason, according to many researchers, is the lack of clear ideas about how modern multimedia and information and communication technologies help to achieve the planned learning outcomes of the Russian language, what should be changed in the content, forms of organization, methods and techniques of training. [1] However, the scientists studied linguistics, experience of successful implementation of certain uses of information and communication technologies: the development and application of electronic educational resources, including remote in professional activities; in teaching Russian as a native, Russian as a foreign language (E.S. Polat, N.A.Algazina, M.Yu. Buharkina, S.I. Gudilina, G.G. Maleva, V.I. Zemzereva, N.V. Ladyzhenskaya, G.I. Pashkovoy, M.A. Tatarinov, etc.).

The analysis of monographic and methodological literature, dissertation research results revealed the following level of knowledge of the problem. Pedagogical sciences provide evidence of positive impact of modern multimedia and communication in Russian language learning technology for the development of communicational skills and positive

\footnotetext{
* Corresponding author: filolog@instrao.ru
} 
qualities of the person learning, partially developed a technique of preparation of the teacher of the Russian language to the use of modern multimedia and information and communication technologies in professional activity. At the same time the need for the development of theoretical and practical issues remain relevant. There is a need for a deeper theoretical and methodological justification of the use of ICT in teaching the Russian language in the sphere of professional and business communication, based on the implementation of the teaching capabilities of modern multi-media, such as differentiated instruction, and focused on the intellectual and personal development of students in the formation of key competences, on the education of the individual, living in an information society.

Thus, of course, today a new approach to the teaching of the Russian language is the use of information and communication, and communication technologies. As it is known, unlike their conventional means, methods and the production of information processing is the use of electronic devices, especially computers.

For definitions relating to media education, computer training in domestic and foreign linguistics, there are many terms. Review of currently existing approaches to media education has revealed a general in the definition of media education as "a process of personal development with the help and on the material of the mass media (the media) with a view to creating a culture of communication with the media, creativity, communication skills, critical thinking skills to perceive fully, interpretation, analysis and evaluation of media texts, teaching different forms of expression using technology "(A.V. Fedorov). In our opinion these objectives should be regarded as a major, if we bear in mind the impact on the process of teaching students, constantly suffering from the impact of media information flows.

In recent years, widely used terms "information technology", "new or emerging information technologies", "information and communication technologies", which showed modern features and computer technology, and tele-communications. Various concepts fixed by these terms define the three main uses of computers in education, namely:

- organization and management of educational process;

- training in the broadest sense of the word - from the training under the guidance of teacher (stationary and distantly) to the use of computer technology for selfeducation;

- study of specific disciplines.

In practice, the use of computers in teaching their native language since the mid 80 -ies of the last century began to be used a variety of applications - text editors, spell checker, electronic dictionaries, as well as spreadsheets, desktop publishing, encyclopedias, games, and other programs. The second stage of the use of computers in teaching the mother tongue, which began in the 90's, is linked to a qualitative change in the technical capabilities of computers and the spread of ICT in the learning process. Such features of how hypertext create a system of cross-references in the text body of information; hypermedia, combining the capabilities of hypertext and multimedia, allow you to use your computer for work on the improvement of all kinds of speech activities (listening, reading, writing, speaking, including aspects as pronunciation and intonation) and for real communication in written and oral form.

The next stage (beginning of the $21^{\text {st }}$ century) in the development of computer-based training consider the use of virtual reality. In the "virtual" classroom - laboratories students are able to operate in an environment simulating a variety of speech situations, it will certainly enhance the possibility of improving speech and cognitive skills, create optimal conditions for the formation of the communicative, socio-cultural competence.

The main feature of the present stage of the use of advanced multimedia and information and communication technologies is the massive and purposeful use of space online, professionally-oriented computer programs of different types: the actual training, application, tool telecommunications - with the aim of creating an integrated computer learning milieu, through which more efficient development of communicative competence of students is ensured.

In modern studies the special power of the Internet to study Russian language in secondary and higher education is emphasized, as Internet resources are available to provide teachers and students with information on various aspects of the study of the Russian language. For example, for high school teachers and students the Internet resources may be interesting, because they are specialized on digital libraries, searching engines, providing search capabilities on the thematic and subject area, job typing (projects, lesson plans, systematic links, interactive exercises) and professional specifics of the students; portals that allow you to participate in discussions, get acquainted with the advanced pedagogical practices.

One of the major problems with the use of the Internet materials for teaching the Russian language is a problem of credibility, scientific and educational value of the content and significance of the information found. Obviously, the genre specificity of sites (news sites, personal pages, information materials, scientific publications, and others) suggests their different content, teachers and students should possess skills to critically perceive the information placed on the Internet to which they refer.

The effective use of modern multimedia and communication technologies in teaching their native language depends on many factors, leading among them are:

- provision of computer equipment and Internet access;

- availability of specialized educational materials and necessary set of programs of various types;

- educational quality used multimedia learning tools;

- an adequate level of general computer literacy of students and teachers; 
- special training for teachers in the field of computer linguistics;

- a special organization of the educational process.

With the apparent significance of all these factors, a key figure in the integration of information and communication technologies and multimedia in the learning process is the teacher who has the necessary qualification and the desire to use them.

Taking into consideration, that a large part of the teachers, who currently works in educational institutions of different levels, had no opportunity to receive the necessary training in the application of modern multimedia and information and communication technologies in teaching at the university, and taking into account that realizing that the development of computer technology passes very rapid pace, we believe that the most important task, indicated in a significant amount of research, must be the organization of the system of retraining and information-methodological support of teachers in the field of computer linguodidactics.

Currently, the theoretical and applied aspects of computer linguistics that are being developed by scientists from different countries can be divided into three areas of research.

The studies on the development of the theoretical aspects of the use of computers in teaching languages belong to the first direction. In the works of this direction the following issues are discussed:

- methodological problems of computer linguistics;

- psychological and pedagogical problems of computerization of language learning;

- questions of typology of computer training materials;

- the problem of assessing the quality of learning software;

- opportunities for the development of communication skills in the learning process with the use of computers and a number of other problems.

The second area includes experimental work on the creation and use in the educational process of computer materials intended for different purposes, forms, and training profiles.
The third area explores ways to integrate computerbased training in general language learning, and developing effective methods of organic use of information and communication technologies and multimedia in the learning process.

These directions of research suggest a comprehensive approach to the study of the problem that appears to be correct. Nevertheless, we consider it necessary to stress the leading problem - the problem of the training of teachers of the Russian language in the project of the educational process with the use of multimedia and information and communication technologies.

\section{References}

1. M.A. Bovtenko, Computer Linguodidactics. Textbook (Flinta: Nauka, Moscow, 2005) [In Rus]

2. V.S. Sobkin, and D.V. Adamchuck, Monitoring of the social impact of information: what has changed in the school for three years? (Institute of Sociology of Education, Moscow, 2008) [In Rus]

3. V.S. Sobkin, and D.V. Adamchuck, The ratio of participants in the educational process to the information and communication technologies (Institute of Sociology of Education, Moscow, 2008) [In Rus]

4. O.G. Khomeriki, Education, science and culture in the global information space. ("Perspective" Publishing House, Moscow, 2008) [In Rus]

5. V.S. Sobkin, Education and information culture. Sociological aspects. Works on the sociology of education. (Center of Sociology of Education, Moscow, 2000) [In Rus]

6. E.A. Bystrova, Training Russian language at schools (Bustard, Moscow, 2007) [In Rus] 